\title{
openheart Guilt by association: paradigm for detecting a silent killer (thoracic aortic aneurysm)
}

\author{
John A Elefteriades, Adam Sang, Gregory Kuzmik, Matthew Hornick
}

To cite: Elefteriades $\mathrm{JA}$, Sang A, Kuzmik G, et al. Guilt by association: paradigm for detecting a silent killer (thoracic aortic aneurysm). Open Heart 2015;2:e000169. doi:10.1136/openhrt-2014000169

Received 3 August 2014 Revised 16 January 2015 Accepted 4 March 2015

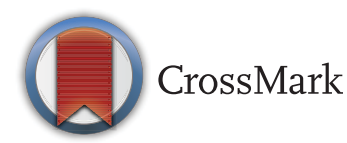

Aortic Institute at Yale-New Haven, Boardman 2, Yale University School of Medicine, New Haven, Connecticut, USA

Correspondence to Professor John A Elefteriades; john.elefteriades@yale.edu

\section{ABSTRACT}

Recent studies have confirmed a close association between various medical conditions (intracranial aneurysm, abdominal aortic aneurysm, temporal arteritis, autoimmune disorder, renal cysts), certain aortic anatomic variants (bovine aortic arch, direct origin of left vertebral artery from aortic arch, bicuspid aortic valve), and family history of aneurysm disease with thoracic aortic aneurysm and dissection. This paper reviews these associations. We propose to capitalise on these associations as powerful and expanding opportunities to diagnose the virulent but silent disease of thoracic aortic aneurysm. This can be accomplished by recognition of this 'guilt by association' with the other conditions. Thus, patients with associated diseases and anatomic variants should be investigated for silent aortic aneurysms. Such a paradigm holds substantial potential for reducing death from the silent killer represented by thoracic aortic aneurysm disease.

\section{INTRODUCTION}

Otto and colleagues have asked the question: "Can we improve the detection of heart valve disease?" 1 Otto and colleagues have also noted that "most patients with a bicuspid aortic valve are unaware of the diagnosis until late in life because symptoms and physical findings often are absent for many years." ${ }^{2}$

Just as occult valve disease must be detected, the same is true of silent aortic aneurysms. A confluence of factors makes the detection of thoracic aortic aneurysm at the same time both essential and difficult.

Detection is essential because of the lethality of this disease. Rupture and dissection are devastating events that take many lives. Aneurysm disease ranks consistently in the top 20 causes of death of human beings. ${ }^{3} 4$ The incidence of thoracic aortic aneurysm is approximately 10 / 100000 population and is roughly equal in men and women. ${ }^{5}$ Aneurysm disease takes the lives of over 15000 Americans per year, more than the number succumbing to HIV disease. ${ }^{3}$ Furthermore, these mortality figures almost certainly represent gross underestimates, as many patients dying in the emergency department with chest pain are signed out as 'myocardial infarction' (MI). ${ }^{3}$ Yet, we know from autopsy studies that many of these deaths in the chest pain centre really represent ruptured or dissected thoracic aortas. Lastly, there has been a bona fide increase in the incidence of thoracic aortic aneurysm that cannot be explained simply by incidental detection from more frequent imaging in the present era. Evidence of this increase comes from studies of relatively geographically isolated populations in regions where postmortem examination is mandatory on death of an individual. $^{36-11}$

Detection is difficult because thoracic aortic aneurysm is a silent disease-a 'silent killer', so to speak. It is thought that only about $5 \%$ of thoracic aortic aneurysms are symptomatic; $95 \%$ of those presenting with a thoracic aortic catastrophe-dissection or rupturehave previously been asymptomatic before this devastating event. Furthermore, even in symptomatic patients, thoracic aortic aneurysm is difficult to diagnose, with over $50 \%$ of emergency department presentations not diagnosed before death. ${ }^{12}$

Therefore, we see that thoracic aortic aneurysm is a silent and lethal disease that usually produces no symptoms until a devastatingly fatal or near-fatal catastrophe ensues. Mortality is said to be $1 \%$ per hour once aortic dissection has occurred. ${ }^{5}$

This paper suggests a detailed paradigm for identification of occult thoracic aortic aneurysms using the concept of 'guilt by association'-that is, assiduously capitalising on detected associated clinical lesions to engender suspicion of possible thoracic aortic aneurysm.

\section{GENERAL BACKGROUND ON THORACIC AORTIC ANEURYSIM}

\section{Genetics of aneurysm disease}

Syndromic patterns of inheritance for thoracic aortic aneurysm and dissection, in which physical manifestations in extra-aortic locations 
permit identification of individuals at risk for thoracic aortic aneurysms, have been known for over 100 years, since Marfan first described the signs and symptoms of the disease that bears his name. ${ }^{513} 14$ The aorta is especially severely disturbed in Marfan disease, with $80 \%$ of patients requiring aortic surgery by the age of 40 , and $100 \%$ by the age of $60{ }^{15}$ Subsequently, other such syndromes have been described, including Ehlers-Danlos and, most recently, Loeys-Dietz. These syndromes, in which the patient's physical appearance provides clues about the aorta, account for approximately $5 \%$ of cases of thoracic aortic aneurysm.

In 1984, my (JAE) distinguished mentor, Dr David Tilson, first reported that some abdominal aortic aneurysms ran in families. ${ }^{16}$

In 1997 and 1999, Milewicz and colleagues and our own group independently reported remarkably similar findings that $21 \%$ of our probands with thoracic aortic aneurysm had a relative with an aneurysm somewhere in the body. Both groups reported remarkably similar Mendelian patterns of inheritance, finding autosomal dominant inheritance predominating (with incomplete penetrance). ${ }^{17} 18$ Patients with this type of inherited transmission of aortic aneurysm, but without phenotypic features of body-wide syndromes, harbour what we call 'familial' or 'non-syndromic' thoracic aortic aneurysm. Their aortas can be extremely thin, as seen in figure 1 .

Milewicz et $a l^{19}$ went on, in ground-breaking work, to identify, largely through linkage analysis of large families with multiple affected individuals, specific genetic mutations that underlie familial aneurysm disease. Together with the previously identified and genetically characterised syndromes (Marfan, Ehlers-Danlos, Loeys-Dietz), this work now provided a roster of seven additional

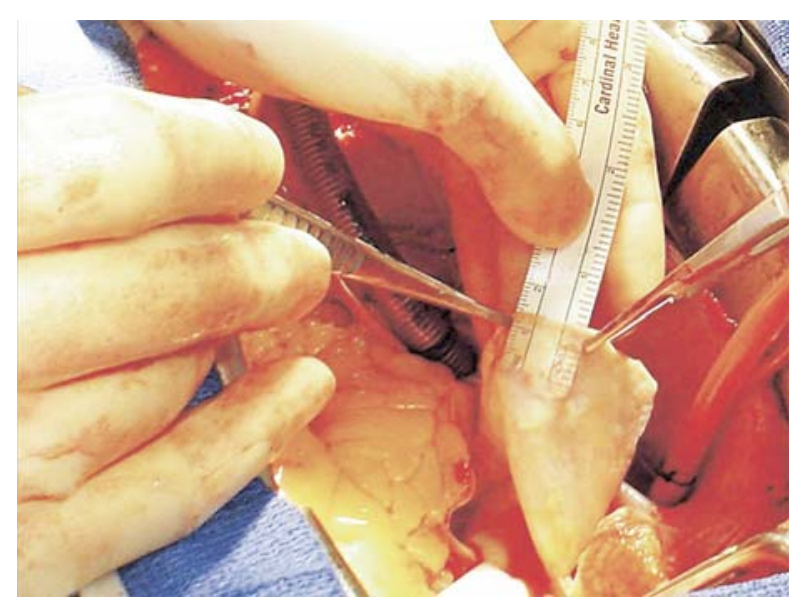

Figure 1 An ascending aorta so thin that the writing on a ruler can be read directly through the wall. It is sobering to think that this was all the tissue restraining the bloodstream and blood pressure in this patient. It is presumed that MMPs participated in the underlying destruction of the aortic wall that resulted in such loss of substance. MMP, matrix metalloproteinases. specific genetic mutations causing thoracic aortic aneurysm: TGFBR-1, TGFBR-2, ACTA 2, MYH11, MYLK, ATS, AOS. However, these mutations, when combined, can only 'explain' about one-fifth of all thoracic aortic aneurysms. Furthermore, in order to be used for screening and detection, these tests would require widespread genotyping of the general population. ${ }^{20}$

Thoracic aortic aneurysm desperately needs biomarkers that can identify asymptomatic, lethal disease in the general population. We have recently reviewed progress in this quest. Suffice to say that little progress has been made. $^{21} 22$ Our group, together with scientists at LifeTech, has recently identified a promising 'RNA Signature' blood test that may be suitable for application to at-risk populations, or even to the general public. ${ }^{23}$ This test, which was successfully replicated (manuscript submitted), but remains in an experimental stage, shows excellent sensitivity and specificity, with an overall accuracy of $80 \%$ at determining, from a blood test alone, whether a human being has a thoracic aortic aneurysm. Also, it accurately distinguishes familial from nonfamilial aneurysms and ascending from descending aneurysms. Further validation studies are underway to package this RNA Signature test as a clinical application. Once a suitable clinical biomarker is identified, death from the thoracic aortic aneurysm can then be prevented by operating before the aneurysm reaches a diameter of $5-6 \mathrm{~cm}$ (see figure 2).

\section{Presentation}

Thoracic aortic aneurysm is asymptomatic in the vast majority of patients, usually being diagnosed via an imaging study carried out for another purpose (echocardiogram (ECHO) or CT scan). In the few patients who

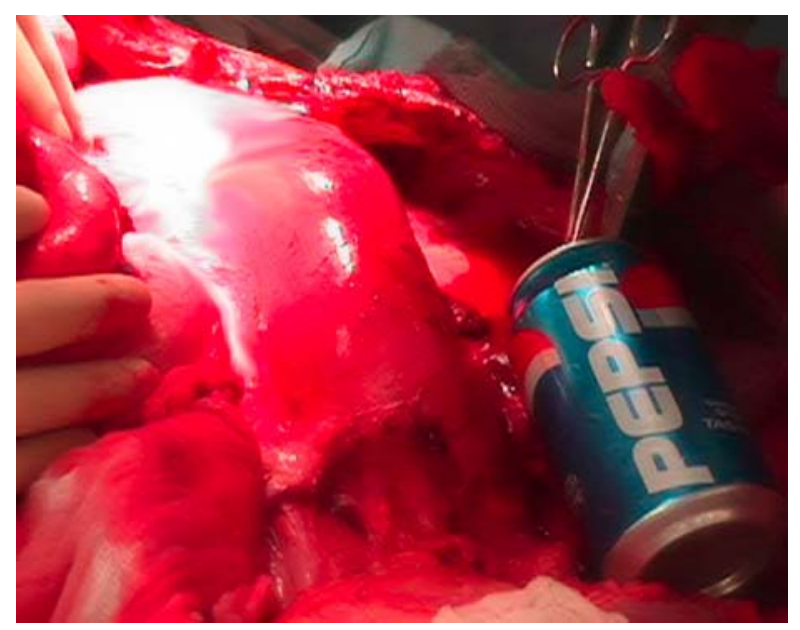

Figure 2 A large thoracoabdominal aneurysm is being resected. The patient's head is to the left and his feet are to the right. The diaphragm has been divided. Note the 'python-like' enlargement of this aorta. A sterile soda can $(6.2 \mathrm{~cm})$ denotes the attainment of a dangerous aortic diameter. If the patient's aorta is approaching the size of a soda can, it must be resected. 
do have premonitory symptoms, these usually take the form of chest pain; if no other causes for chest pain are found, the pain can fairly be presumed to originate from the thoracic aneurysm. When aortic dissection does occur, this is manifested by sudden onset of severe chest pain (knife-like or tearing in nature), usually following an extreme physical or emotional strain. ${ }^{5} 1314$ Because any branch of the aorta, from the coronary arteries to the iliacs, can be occluded by the dissection process, aortic dissection can resemble primary disease of literally any organ, thus earning the well-deserved reputation as 'the great masquerader' ${ }^{12}$ (see figure 3).

\section{Differential diagnosis}

It is important for physicians on the front lines (usually in the emergency department) to maintain a high index of suspicion for acute aortic dissection, especially in a patient with any of the stigmata to be discussed below in this paper. D-dimer is an extremely useful test, as it is essentially $100 \%$ sensitive (but not specific). If the D-dimer is not elevated, the patient does not have an aortic dissection. ${ }^{21}$ In case of any suspicion of aortic dissection, a cardiac ECHO and/or a CT scan are essential to rule out the diagnosis. Both modalities are highly sensitive for ascending aortic dissection. MRI is also sensitive and specific, but this modality is usually less easily available than ECHO and CT scan. ${ }^{5}$

\section{Differentiation from MI}

Acute ascending aortic dissection can masquerade as MI (or even produce a bona fide MI from coronary occlusion by the dissection flap). In this era of focus on rapid door-to-balloon time for acute MI, patients with aortic dissection can erroneously be taken to the catheterisation laboratory for angioplasty, when they really need to go to the operating room for dissection repair. The heparin and other antithrombotic drugs given for acute MI can incite or encourage bleeding from the aorta. (This was the mode of death for the actor John Ritter, which resulted in the precautionary 'Ritter's Rules' intended to guide physicians towards diagnosis of aortic dissection.) A chest X-ray or ECHO performed before or in the catheterisation laboratory can go a long way towards preventing the lethal scenario of misdiagnosis of acute aortic dissection as a primary MI. ${ }^{24}$ Also, noticing the stigmata of aortic disease to be discussed below can
Figure 3 Schematic

representation of the four ways in which acute aortic dissection can take a patient's life: (1) intrapericardial rupture, leading to cardiac tamponade; (2) free rupture, usually into the left pleural space; (3) acute aortic insufficiency, which is usually very poorly tolerated, even leading to shock; (4) occlusion of virtually any branch of the aorta, from the coronary arteries to the iliacs. Because any branch of the aorta can be occluded by the dissection process, aortic dissection can mimic disease of any organ of the body, earning its well-deserved reputation as 'the great masquerader'. Reproduced with permission from Elefteriades et al. ${ }^{39}$

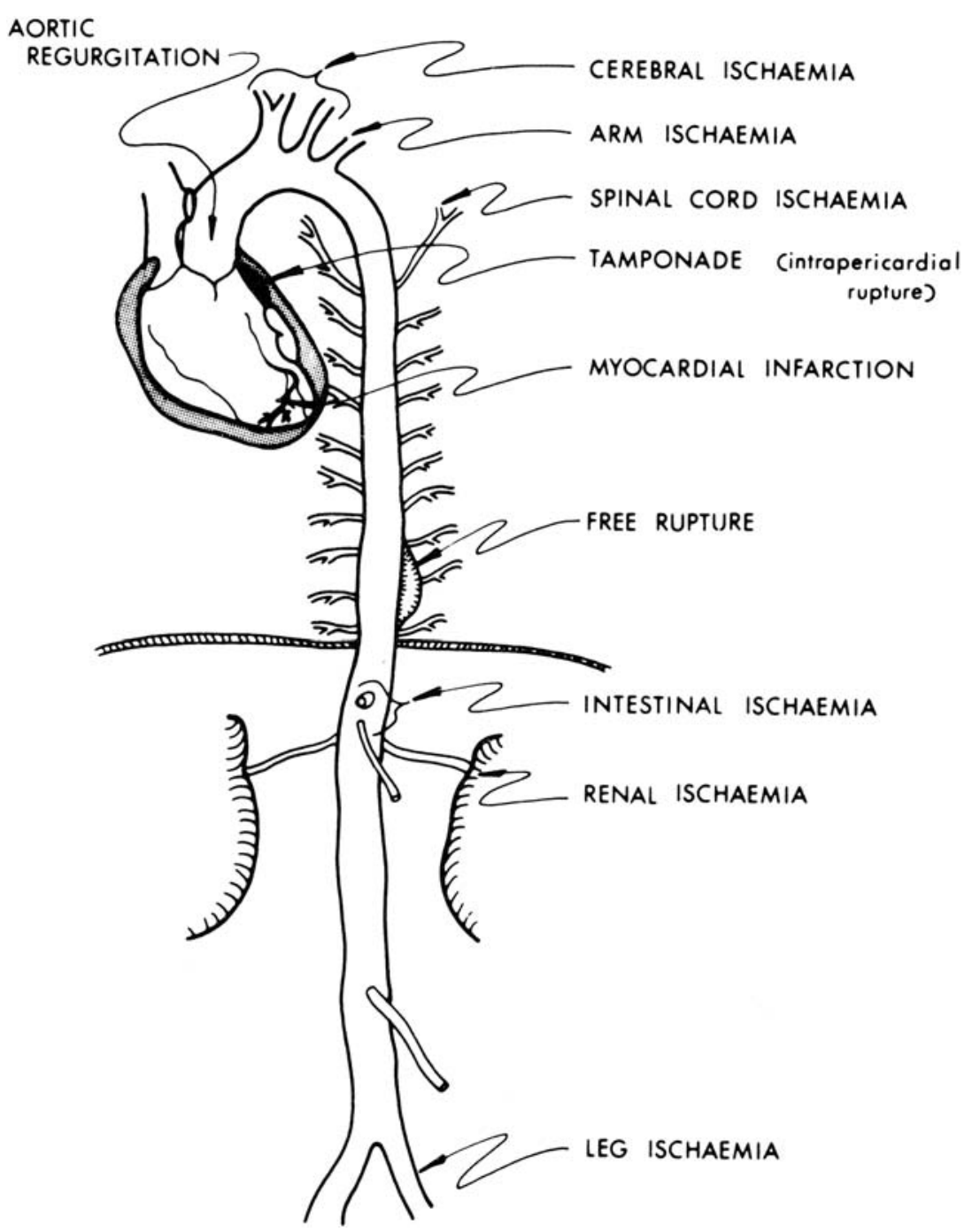


help steer one's diagnosis towards aortic dissection in a genetically susceptible patient.

\section{Treatment}

In general terms, descending aortic dissections are treated medically unless specific complications arise (rupture, organ malperfusion, impending rupture). This is called the 'complication-specific' approach ${ }^{25}$ (see table 1). For descending dissection, when surgical treatment is necessary, interventional techniques usually suffice.

For acute ascending aortic dissection, treatment is surgical in all viable candidates, as the risk of death from rupture, cardiac tamponade, acute aortic insufficiency or organ ischaemia is great. Ascending aortic replacement, with or without aortic valve repair or replacement, is the procedure of choice. In patients who are not surgical candidates, because of stroke, malignancy, advanced age or profound comorbidities, so-called 'anti-impulse therapy' is instituted. This comprises a $\beta$-blocker to decrease the force of cardiac contraction and an afterload reducing agent (usually sodium nitroprusside) to lower the blood pressure (see figure 4). We usually drop the heart rate to 60 and the blood pressure to $100 \mathrm{~mm} \mathrm{Hg}$ systolic (unless cerebral or renal hypoperfusion become manifest).

For acute ascending aortic dissection, surgical therapy now produces survival rates of $85 \%$ or better, especially in specialised centres. Without surgery, it used to be said, outcome was uniformly lethal. Today, with careful intensive care unit management and anti-impulse therapy, over one-half of non-operative patients can be saved to survive the acute event. ${ }^{26}$

In the case of abdominal aortic aneurysm, because the abdominal aorta is easily visualised by ECHO, a special opportunity is afforded by routine screening. It has been determined that a negative screen for abdominal aortic aneurysm at age 65 (Medicare age) assures that the screened patient will never die of ruptured aortic aneurysm during his remaining life expectancy. ${ }^{27}$

\section{'Associates' of thoracic aortic aneurysm}

Our group has recently identified certain clinical and anatomic 'associates' of thoracic aneurysm, with which thoracic aortic aneurysm cohabits. In general, individuals

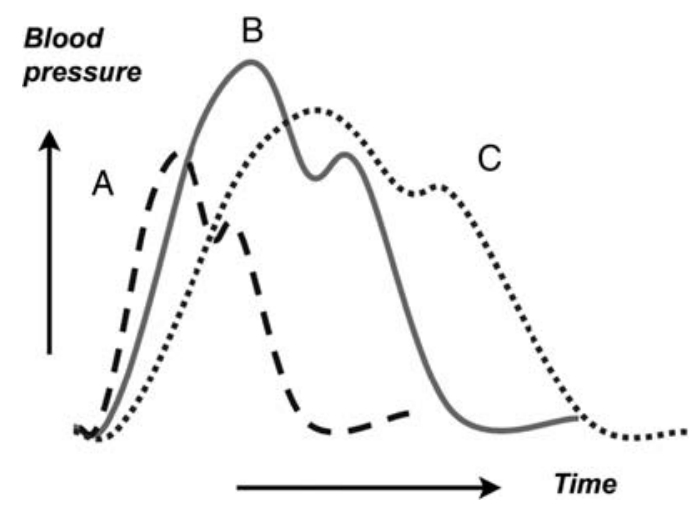

Figure 4 Pharmacological anti-impulse therapy. Diagram of aortic pressure curves under various conditions. The continuous line $(B)$ represents the baseline state.

Administration of a vasodilator agent such as nitroprusside is represented by the dashed curve $(A)$. There is significant decrease in pressure levels and acceleration in heart rate, but this is accompanied by a steepest slope of the ascending portion of the curve (increased dp/dtmax). $\beta$-Blockade administration is represented by the dotted line (C). Although the degree of pressure lowering is usually smaller, the drug's negative inotropic and chronotropic effects result in decreased impulse and dp/dtmax. Reproduced with permission from Sanz et al. ${ }^{41}$

with these associated conditions harbour thoracic aortic aneurysms with a higher prevalence than the general population, so these conditions may be used systematically to identify at-risk groups.

\section{Intracranial aneurysm}

A 2010 report found that about $9 \%$ of patients with thoracic aortic aneurysm had concurrent intracranial aneurysms. $^{28}$ A 2014 report evaluated the converse relationship: $5 \%$ of patients with intracranial aneurysm have concurrent thoracic aneurysms. ${ }^{29}$ This relationship suggests the possibility to identify many thoracic aortic aneurysms merely by imaging the thorax of patients with brain aneurysms.

\section{Bovine aortic arch}

A 2013 report found that bovine aortic arch, heretofore considered a benign variant, is closely associated with the

Table 1 General treatment paradigms for acute aortic dissection (see text)

\section{General treatment paradigms for acute aortic dissection}

\begin{tabular}{|c|c|c|}
\hline & Primary treatment & Alternate treatment \\
\hline $\begin{array}{l}\text { Type A dissection } \\
\text { (ascending) }\end{array}$ & Surgery (ascending aortic replacement) & $\begin{array}{l}\text { Anti-impulse } \mathrm{Rx} \\
\quad \beta \text {-blockers } \\
\text { Afterload reducers }\end{array}$ \\
\hline $\begin{array}{l}\text { Type B dissection } \\
\text { (descending) }\end{array}$ & $\begin{array}{l}\text { Complication-specific approach } \\
\text { Uncomplicated: Med Rx } \\
\text { (anti-impulse Rx) }\end{array}$ & $\begin{array}{l}\text { Complicated: } \\
\text { Rupture-surgery/endovascular } \\
\text { Impending rupture-endovascular } \\
\text { Malperfusion-fenestration } \\
\text { (surgical or endovascular) }\end{array}$ \\
\hline
\end{tabular}


presence of thoracic aortic aneurysm. ${ }^{30}$ Malone $e t a l^{1}$ have independently confirmed this relationship. This provides an opportunity to diagnose many thoracic aortic aneurysms by closely following patients who have a bovine anatomy detected incidentally on CT performed for other reasons. Yet, data from our institution indicate that another aortic arch anomaly, direct origin of the left vertebral artery from the aortic arch (instead of from the left subclavian artery), is similarly associated with the presence of thoracic aortic aneurysm. ${ }^{32}$

\section{Abdominal aortic aneurysm}

This year, Hultgren $e t a l^{33}$ reported that $27 \%$ of patients with abdominal aortic aneurysm had concurrent descending thoracic aortic aneurysms. Female gender increased the OR of a concurrent descending aortic aneurysm to 3.3 (and advanced age increased the OR to 2.4 , and hypertension to $\mathrm{OR}=1.8$ ).

\section{Renal cysts}

An association between thoracic aortic aneurysm and polycystic kidney disease has been known from case reports for many years. A recent study has shown that even simple renal cysts, without a full polycystic pattern, seem to associate with thoracic aortic aneurysm. ${ }^{34}$ The prevalence of simple renal cysts is $37.1 \%, 57.0 \%, 44.1 \%$ and $46.7 \%$ for patients with ascending aortic aneurysm, descending aortic aneurysm, type A aortic dissection and type B aortic dissection, respectively. These numbers are higher than the prevalence of simple renal cysts in the general population. This observation provides an opportunity to identify more patients with thoracic aortic aneurysm simply by extending ECHO or CT from the abdomen to include the chest. (We have also noted an association with liver cysts, but this is still being investigated.)

\section{Bicuspid aortic valve}

The association between bicuspid aortic valve and ascending aortic aneurysm is well known. ${ }^{35}$ Should a bicuspid aortic valve be discovered, attention should be paid to image the ascending aorta (and probably the remainder of the aorta as well).

\section{Family history}

Of course, a gold mine of detection can be had by imaging (by cardiac ECHO, CT or MRI) the family members of patients with known thoracic aortic aneurysms.

\section{Thumb-palm test}

We have noted informally that many patients who are referred to our institution with documented thoracic aortic aneurysms can cross their thumb beyond the edge of the flat palm-a positive 'thumb-palm' test-even in the absence of other stigmata of Marfan syndrome or other connective tissue diseases. ${ }^{36}$ These patients with a positive thumb-palm test, we find, have excessive long bones and lax joints-indicators of connective tissue disease $^{36}$ (see figure 5). We feel that imaging the aorta in such patients with a positive thumb-palm sign is warranted. Simple attention to this quickly assessed physical finding, which can be included in routine physical examination, may be able to identify patients with thoracic aortic aneurysm who are otherwise asymptomatic.

\section{Temporal arteritis (and other autoimmune disorders)}

Very recently, an association between temporal arteritis and aortic aneurysm was identified. ${ }^{37-39}$ The risk is significant, but relatively low $(\mathrm{OR}=2)$. Investigation for aneurysm disease is recommended if any other traditional aneurysm risk factors are present.

\section{Aortic coarctation}

Aortic coarctation is often associated with ascending or descending aortic aneurysm. For adults, whatever test (ECHO or CT) has disclosed the coarctation has usually also detected the ascending or descending aneurysm. Bicuspid valve is often an accompanying feature. For children, many years may intervene between manifestation of the coarctation and later development of the thoracic aortic aneurysm.

\section{CONCLUSION}

As we have seen, thoracic aortic aneurysm is a largely asymptomatic but potentially lethal syndrome. Thus,

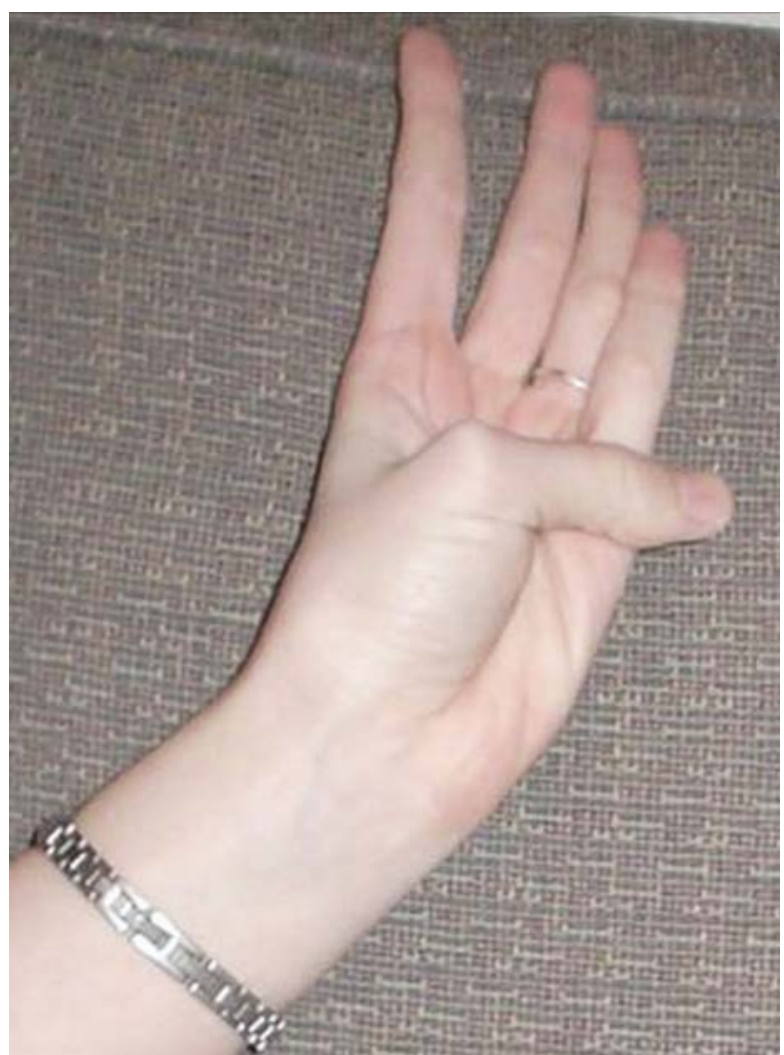

Figure 5 The thumb-palm sign. Note the extension of the thumb beyond the border of the flat palm, indicating excessive long bones and lax joints. This indicates connective tissue disease and should prompt an aneurysm investigation. 
Table 2 'Guilt by association' indicators for the patient himself

\begin{tabular}{|c|c|c|}
\hline \multicolumn{3}{|l|}{ Regarding patient himself } \\
\hline Situation & Recommendation & Comments \\
\hline $\begin{array}{l}\text { Abdominal aortic } \\
\text { aneurysm (AAA) }\end{array}$ & $\begin{array}{l}\text { Image patient for } \\
\text { TAA }\end{array}$ & $\begin{array}{l}27 \% \text { overlap expected } \\
\text { (higher in women) }\end{array}$ \\
\hline Intracranial aneurysm & $\begin{array}{l}\text { Image patient for } \\
\text { TAA }\end{array}$ & $5 \%$ overlap expected \\
\hline Bicuspid aortic valve & $\begin{array}{l}\text { Image patient for } \\
\text { TAA }\end{array}$ & $\begin{array}{l}\text { TAA overwhelmingly } \\
\text { likely in patient at } \\
\text { some point (unless other cause of } \\
\text { death supervenes) }\end{array}$ \\
\hline Coarctation of the aorta & $\begin{array}{l}\text { Image patient for } \\
\text { TAA }\end{array}$ & Association with TAA \\
\hline Bovine aortic arch & $\begin{array}{l}\text { Image patient for } \\
\text { TAA }\end{array}$ & Association with TAA \\
\hline $\begin{array}{l}\text { Origin of left vertebral } \\
\text { artery directly from } \\
\text { aortic arch }\end{array}$ & $\begin{array}{l}\text { Image patient for } \\
\text { TAA }\end{array}$ & Association with TAA \\
\hline Polycystic kidney disease & $\begin{array}{l}\text { Image patient for } \\
\text { TAA }\end{array}$ & Association with TAA \\
\hline $\begin{array}{l}\text { Intra-abdominal simple } \\
\text { cysts (kidney or liver) }\end{array}$ & $\begin{array}{l}\text { Image patient for } \\
\text { TAA }\end{array}$ & Association with TAA \\
\hline Temporal arteritis & $\begin{array}{l}\text { Image patient for } \\
\text { TAA }\end{array}$ & Twofold odds for AAA \\
\hline $\begin{array}{l}\text { Autoimmune syndromes (Bechet's, Reiter's, ankylosing } \\
\text { spondylitis, early onset osteoarthritis) }\end{array}$ & $\begin{array}{l}\text { Image patient for } \\
\text { TAA }\end{array}$ & Association with TAA \\
\hline
\end{tabular}

detection among the general population is key. Although the thoracic aortic aneurysm itself is likely silent, in this paper we have focused on other concomitant detectable manifestations that frequently accompany thoracic aortic aneurysm. We urge that particular attention be paid to these concomitant, detectable manifestations of thoracic aneurysm disease. When these concomitant manifestations are noted, imaging (ECHO, CT, MRI) can be performed to search for thoracic aortic aneurysm. This is what we mean by our title of 'guilt by association': thoracic aortic aneurysm can be detected by its various physical associated manifestations, despite the clinical silence of the aneurysm itself.

Thus, altogether, these observations permit a detection paradigm of 'guilt by association'-that is, identifying asymptomatic thoracic aortic aneurysms by imaging patients with other known 'associates' of this disease. We have enumerated the potential candidates for such 'guilt by association' screening in tables 2 and 3. It is likely that shared underlying biochemical pathways are responsible for both thoracic aortic aneurysms and many of these other 'associated' clinical conditions.

We believe that a pattern of concerted investigation of patients with the other findings or diseases indicated in tables 2 and 3 can detect a large number of the patients in whom an asymptomatic but potentially lethal thoracic aortic aneurysm resides. Once a thoracic aortic aneurysm is detected, death can effectively be prevented by skilful clinical decision-making and timely surgical intervention. Thus, we feel that adopting a vigorous 'guilt by

Table 3 Guilt by association indicators among family members

\begin{tabular}{|c|c|c|}
\hline \multicolumn{3}{|l|}{ Regarding family members } \\
\hline Situation & Recommendation & Comments \\
\hline $\begin{array}{l}\text { Patient affected by TAA (syndromic } \\
\text {-Marfan, Ehler-Danlos, } \\
\text { Loeys-Dietz) }\end{array}$ & $\begin{array}{l}\text { Image and genotype all first-order } \\
\text { family members }(\mathrm{ECHO} \pm \mathrm{CT} \text { scan })\end{array}$ & $\begin{array}{l}\text { Autosomal dominant inheritance (with incomplete } \\
\text { penetrance) }\end{array}$ \\
\hline $\begin{array}{l}\text { Patient affected by TAA } \\
\text { (non-syndromic) }\end{array}$ & $\begin{array}{l}\text { Image all first-order family members } \\
\text { (ECHO } \pm C T \text { scan) }\end{array}$ & $\begin{array}{l}21 \% \text { likelihood of family member with known } \\
\text { TAA (additional affected family members likely to } \\
\text { be identified by imaging) }\end{array}$ \\
\hline $\begin{array}{l}\text { Patient affected by bicuspid aortic } \\
\text { valve }\end{array}$ & $\begin{array}{l}\text { Image all first-order family members } \\
\text { for bicuspid valve, TAA }\end{array}$ & $8 \%$ likelihood of family member being affected \\
\hline
\end{tabular}




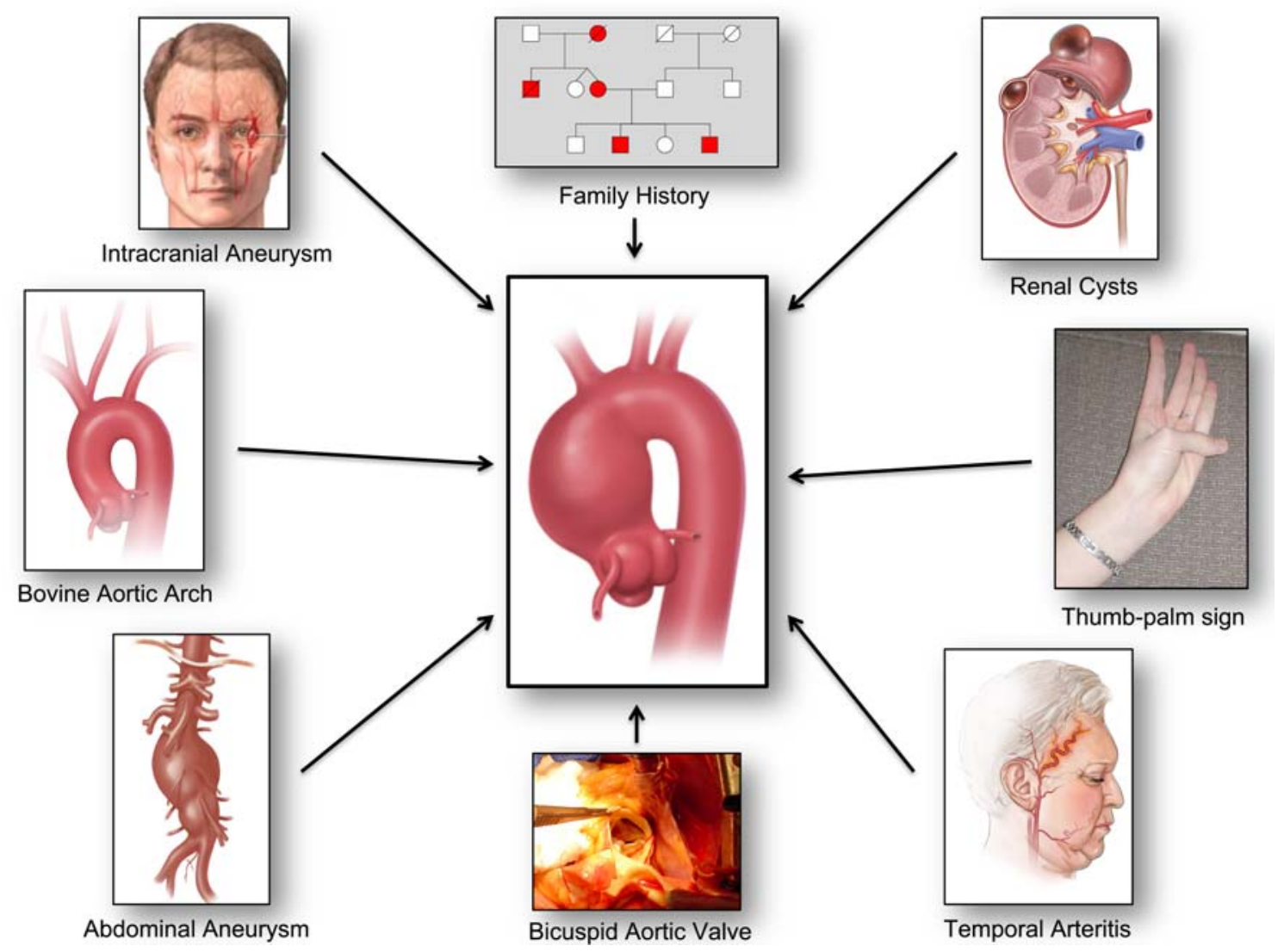

Figure 6 Paradigm of "Guilt by Association" for detection of silent thoracic aortic aneurysms.

association' approach may serve to decrease death from thoracic aortic aneurysm, even before the 'holy grail' of a suitable and effective screening biomarker is achieved.

We recommend such an approach of detection through 'guilt by association' (figure 6).

Contributors JAE conceived this article and wrote the first draft, which was reviewed by all the coauthors. Each coauthor participated in a major way in the Yale studies which form the basis for this review article. AS and GK both contributed to the studies that underlie this report, and reviewed, edited and approved the final manuscript. MH participated in the data collection, data analysis, writing and editing of this paper.

Competing interests JAE consults for Baxter, Covidien, Datascope and CryoLife, and has had a recent grant from Medtronic.

Provenance and peer review Not commissioned; externally peer reviewed.

Open Access This is an Open Access article distributed in accordance with the Creative Commons Attribution Non Commercial (CC BY-NC 4.0) license, which permits others to distribute, remix, adapt, build upon this work noncommercially, and license their derivative works on different terms, provided the original work is properly cited and the use is non-commercial. See: http:// creativecommons.org/licenses/by-nc/4.0/

\section{REFERENCES}

1. Arden C, Chambers JB, Sandoe J, et al. Can we improve the detection of heart valve disease? Heart 2014;100:271-3.

2. Lewin MB, Otto $C$. The bicuspid aortic valve: adverse outcomes from infancy to old age. Circulation 2005;111:832-4.

3. Elefteriades JA, Rizzo JA. Epidemiology: incidence, prevalence, and trends. In: Elefteriades JA. ed. Acute aortic disease. New York: Informa Healthcare, 2007:89-98.
4. Centers for Disease Control. Twenty leading causes of death, United States. 2010. All causes. All races, both sexes. http://webappa.cdc. gov/sasweb/ncipc/leadcaus10.html (accessed 17 Nov 2013).

5. Elefteriades JA, Olin JW, Halperin JL. Diseases of the Aorta. In: Fuster V, ed. Hurst's the heart. 13th edn. New York: McGraw Hill, 2011:2261-89.

6. Acosta $\mathrm{S}$, Ogren $\mathrm{M}$, Bengtsson $\mathrm{H}$, et al. Increasing incidence of ruptured abdominal aortic aneurysm: a population-based study. J Vasc Surg 2006;44:237-43.

7. Clouse WWE, Hallett JW, Schaff HV, et al. Improved prognosis of thoracic aortic aneurysms: a population-based study. JAMA 1998;280:1289-98.

8. Gillum RF. Epidemiology of aortic aneurysm in the United States. $J$ Clin Epidemiol 1995;48:1289-98.

9. Reitsma JB, Pleumeekers HG, Hoes AW, et al. Increasing incidence of aneurysms of the abdominal aorta in The Netherlands. Eur J Vasc Endovasc Surg 1996;12:446-51.

10. Best VA, Price JF, Fowkes FG. Persistent increase $\mathrm{n}$ the incidence of abdominal aortic aneurysm in Scotland, 1981-2000. Br J Surg 2003;90:1510-15.

11. Filipovic M, Goldacre MJ, Roberts SE, et al. Trends in mortality and hospital admission rates for abdominal aortic aneurysm in England and Wales. Br J Surg 2005;92:968-75.

12. Elefteriades $\mathrm{JA}$, ed. Legal considerations in acute aortic disease. In: Acute aortic disease. New York: Informa Healthcare, 2007:331-46.

13. Elefteriades JA. Thoracic aortic aneurysm: reading the enemy's playbook. Curr Probl Cardiol 2008;33:203-77.

14. Elefteriades JA, ed. Acute aortic disease. New York: Informa Healthcare, 2007.

15. Samadi A, Detaint D, Roy C, et al. Surgical management of patients with Marfan syndrome: evolution throughout the years. Arch Cardiovasc Dis 2012;105:84-90.

16. Tilson MD, Seashore MR. Fifty families with abdominal aortic aneurysms in two or more first-order relatives. Am J Surg 1984;147:551-3.

17. Biddinger $\mathrm{A}$, Rocklin M, Coselli $\mathrm{J}$, et al. Familial thoracic aortic dilatations and dissections: a case control study. J Vasc Surg 1997;25:506-11. 
18. Coady MA, Davies RR, Roberts M, et al. Familial patterns of thoracic aortic aneurysms. Arch Surg 1999;13:361-7.

19. Milewicz DM, Carlson AA, Regalado ES. Genetic testing in aortic aneurysm disease: PRO. Cardiol Clin 2010;28:191-7.

20. Pomianowski P, Elefteriades JA. The genetics and genomics of thoracic aortic disease. Ann Cardiothorac Surg 2013;2:271-9.

21. Trimarchi S, Sangiorgi G, Sang X, et al. In search of blood tests for thoracic aortic diseases. Ann Thorac Surg 2010;90:1735-42.

22. van Bogerijen GH, Tolenaar JL, Grassi V, et al. Biomarkers in TAA: the Holy Grail. Prog Cardiovasc Dis 2013;56:109-15.

23. Wang Y, Barbacioru CC, Shiffman D, et al. Gene expression signature in peripheral blood detects thoracic aortic aneurysm. PLOS ONE 2007;2:e1050.

24. Guo XM, Bonde P. Ruptured pneumococcal aortic aneurysm presenting as ST-elevation myocardial infarction: case-report and literature review. AORTA, in press.

25. Elefteriades JA, Hartleroad J, Gusberg RJ, et al. Long-term experience with descending aortic dissection: the complication-specific approach. Ann Thorac Surg 1992;53:11-21.

26. Scholl FG, Coady MA, Davies R, et al. Interval or permanent nonoperative management of acute type A aortic dissection. Arch Surg 1999;134:402-5.

27. U.S. Preventive Services Task Force. Abdominal aortic aneurysm: screening. June 2014.

28. Kuzmik GA, Feldman M, Tranquilli M, et al. Concurrent intracranial and thoracic aortic aneurysms. Am J Cardiol 2010;105:417-20.

29. Kuzmik GA, Bulsara KR, Ciarleglio MM, et al. Thoracic aortic aneurysms in patients with intracranial aneurysms. (Submitted).

30. Hornick M, Moomiaie R, Mojibian $\mathrm{H}$, et al. "Bovine" aortic arch-a marker for thoracic aortic disease. Cardiology 2012;123:116-24.

31. Malone CD, Urbania TH, Crook SE, et al. Bovine aortic arch: a novel association with thoracic aortic dilation. Clin Radiol 2012;67:28-31.
32. Dumfarth J, Chou AS, Ziganshin BA, et al. Atypical aortic arch branching variants: A novel marker for thoracic aortic disease. J Thorac Cardiovasc Surg. Published Online First: 14 Feb 2014. doi:10.1016/j.jtcvs.2015.02.019.

33. Hultgren R, Larsson E, Wahlgren CM, et al. Female and elderly abdominal aortic aneurysm patients more commonly have concurrent thoracic aortic aneurysm. Ann Vasc Surg 2012;26:918-23.

34. Ziganshin BA, Theodoropoulos P, Salloum MN, et al. Simple renal cysts as predictors of thoracic aortic disease. Circulation 2013;128 A17434.

35. Friedman T, Mani A, Elefteriades JA. Bicuspid aortic valve: clinical approach and scientific review of a common clinical entity. Expert Rev Cardiovasc Ther 2008;6:235-48.

36. Elefteriades JA, Farkas EA. Thoracic aortic aneurysm: clinically pertinent controversies and uncertainties. J Am Coll Cardiol 2010;55:841-57.

37. Robson JC, Kiran A, Maskell J, et al. The relative risk of aortic aneurysm in patients with giant cell arteritis compared with the general population of the UK. Ann Rheum Dis 2015;74: 129-35.

38. Slobodin G, Naschitz JE, Zuckerman E, et al. Aortic involvement in rheumatic diseases. Clin Exp Rheumatol 2006;24(2 Suppl 41): S41-7.

39. Sato O, Takagi A, Miyata T, et al. Aortic aneurysms in patients with autoimmune disorders treated with corticosteroids. Eur J Vasc Endovasc Surg 1995;10:366-9.

40. Elefteriades JA, Tribble C, Geha A, et al. House officer's guide to ICU care. 3rd edn. Minnesota: CardioText, 2013.

41. Sanz J, Einstein J, Fuster V. Acute aortic dissection: anti-impulse therapy. In: Elefteriades JA, ed. Acute aortic disease. New York: Informa Healthcare, 2007:229-49. 